\title{
Editorial
}

\section{Communities at risk}

The annual costs of keeping a person in prison or in a mental hospital exceed those of sending him to college. The high rate of recidivism does not support a view of prisons as rehabilitative or corrective institutions. Most prisons and psychiatric hospitals offer primarily custodial care of many of their inmates, and this is done largely to protect the communities into which these inmates would otherwise be released.

Despite scientific advances, it is still not possible to reduce the risk to the point at which we can abandon prisons and mental institutions (or other providers of custodial care) as cost-ineffective. If we gave each felon half of what it costs to keep him in prison, in return for his agreement not to harm anyone, we would not be willing to risk his violating the agreement. Nor would we find it just, or sensible, considering that many normal persons work hard to earn less; it would create an incentive to become a one-time felon. Making prisons more humane, with better educational and career-building facilities could, however, be regarded as a similar incentive for certain persons.

The modern trend is to create half-way houses, or more generally part-way houses, where 'part' can vary from 0 to 1 . (A maximum security institution is a 0 -way house and residency in the community as a full-fledged member is a 1-way house.). Many residents of a community accept the idea of a part-way house, but prefer a part-way house to be in locations other than next to their own, especially when 'part' is less than 'half'. A key feature of a part-way house is the restriction on the number of opportunities a deviant has for harming others. In an isolation cell such opportunities are nearly 0 , and in an open community they are at a maximum. Another key feature is that the deviant gradually becomes reinforced for and accustomed to behaving normally as he moves from a part-1-way house to a part-2-way house, where part-1 exceeds part-2, e.g. from a quarter-way house to a

North-Holland Publishing Company

Human Systems Management 2 (1981) 237-238 three-quarters-way house. A third key feature is that such a part-2-way house costs the community less to maintain than a part-1-way house. But what about the cost to the community in terms of anxiety, fear, and objective risks of actual harm? The major reason that people move from a community appears to be a helpless feeling of insecurity or lack of safety.

Analysis of data that is probably available could shed light on some of the issues. The number of crimes or harmful acts per year for three subpopulations could be compared. First is that number per resident in a half-way house. Second is that number for newly released felons ( 0 -way house). Third is the corresponding number for a person at large in the general population. Undoubtedly, the second is greater than the third. If the first is roughly the same as the third, half-way houses should be more acceptable than if it were close to the second.

Studies in social psychiatry have estimated that one in five who walk the streets (e.g. in midtown Manhattan) are sufficiently psychotic to require hospitalization to keep them from harming themselves or others unintentionally. Even if this figure is vastly exaggerated and if we adjoin the fraction of the population likely to harm others intentionally we may obtain a figure of 10 percent of the population at large being a potential menace to the community. If each of these persons' contacts had a 0.01 chance of being harmed, and if each potential harmer contacted 1000 different persons during the course of his lifetime, we could expect ten victims per harmer's lifetime. If the harmers had no common victims, and if they all had about the same remaining lifetime, then everyone in the population is likely to be harmed once. There are not enough custodial care institutions to accomodate 10 percent of the population. Nor are they being built fast enough to keep up with population growth. Moreover, there is no effective way of identifying the 10 percent before they have harmed others and in many cases not even afterwards. Nor is it feasible to maintain them in custodial care for indefinitely long periods. 
Classical management science might be (mis)interpreted to imply that the most cost-effective way to manage this problem is to permanently and reliably separate known harmers from opportunities to do harm by permanently destroying either the community at risk or the harmers. But that is not human management of a very human system. Human systems management must be able to provide better options, perhaps in making part-way houses work better, or by taking a radically new approach. We cannot wait for research to help prevent, cure or treat deviants. Nor is this a problem for medicine, social work, law enforcement or criminology alone. It is a genuine human systems problem. The need for creative ideas that build such options stands as a challenge to readers of this journal.

Manfred KOCHEN

The University of Michigan 